\title{
Pregnancy Achieved Using Donor Eggs in Cancer Survivors with Treatment-Induced Ovarian Failure: Obstetric and Perinatal Outcome
}

\author{
Anna Marklund, MD,1,3 Josefine Nasiell, MD, PhD, 2,4 Ann-Sofie Berger, MD, 4,5 \\ Antonia Fagerberg, MD, ${ }^{4,5}$ and Kenny A. Rodriguez-Wallberg, MD, $\mathrm{PhD}^{1,5}$
}

\begin{abstract}
Background: Egg donation is a common fertility treatment in female cancer survivors with reproductive wish and iatrogenic ovarian failure. We examined whether women previously treated for cancer have a higher risk of pregnancy complications after egg donation treatments when compared to women without cancer history.

Methods: In this prospective cohort treated during 2003-2015 at a single center, 31 women with previous history of cancer achieved 25 deliveries and 212 women without cancer history achieved 244 deliveries. All egg donor treatments were performed with a strict policy of single embryo transfer to reduce pregnancy and perinatal complications. Data were analyzed using logistic regression with adjustment for relevant confounders, to estimate adjusted odds ratios (aORs) and 95\% confidence intervals (CIs) for perinatal and obstetric outcomes. Women without previous history of cancer were used as the reference group in the regression models.

Results: Women with a history of cancer presented with a significantly increased risk of pregnancy complications, including preterm birth (aOR 5.54, 95\% CI 2.01-15.31) and preeclampsia (aOR 2.79, 95\% CI 1.077.34), compared to women without cancer history.

Conclusions: The findings of this study suggest that the risks of preterm birth and preeclampsia in women with prior cancers who become pregnant by egg donor treatment significantly exceed those of women without cancer history undergoing similar treatments. As pregnancies using donor eggs are already acknowledged of higher risk for hypertensive pathologies, this study alerts toward characterization of specific increased risks in women who are cancer survivors to provide adapted pregnancy monitoring.
\end{abstract}

Keywords: cancer, egg donation, perinatal outcomes, obstetric outcomes

\section{Introduction}

$\mathbf{F}$ ULFILling THE DESIRE to have children is important to cancer survivors of reproductive age. ${ }^{1,2}$ Different methods for fertility preservation have been developed to offer them the possibility to get genetically related children. ${ }^{3}$ Another valid option to experience pregnancy and biological parenthood for women with iatrogenic ovarian failure is to use donor eggs.

Still, concerns have been raised regarding the potential risks of pregnancy due to previous cancer treatments. While chemotherapy-specific effects on pregnancies in longterm survivors of childhood cancer are reported to be few, ${ }^{4}$ radiotherapy (RT) of the pelvis has been associated to higher rates of miscarriage, premature delivery, and low birthweight, ${ }^{5,6}$ in particular if high doses were applied. ${ }^{7}$ Data on maternal and perinatal outcomes in the broader population of women with prior cancers are scarce. More importantly, data are particularly lacking on the performance of third-part reproductive treatments using donor eggs in this population.

To date, accumulating evidence suggests that egg donor treatment in itself is a significant and independent risk factor for pregnancy complications. ${ }^{8,9}$ Some studies indicate a two- to three-fold increased risk of gestational hypertension and preeclampsia, ${ }^{10-12}$ a higher incidence of gestational

Departments of ${ }^{1}$ Oncology-Pathology, ${ }^{2}$ Clinical Science, Intervention and Technology - CLINTEC, Karolinska Institutet, Stockholm, Sweden.

${ }^{3}$ Department of Obstetrics and Gynecology, Södersjukhuset, Stockholm, Sweden.

${ }^{4}$ Department of Obstetrics and Gynecology Clintec, Karolinska University Hospital, Stockholm, Sweden.

${ }^{5}$ Reproductive Medicine, Karolinska University Hospital, Stockholm, Sweden.

(c) Anna Marklund et al. 2018; Published by Mary Ann Liebert, Inc. This Open Access article is distributed under the terms of the Creative Commons Attribution Noncommercial License (http://creativecommons.org/licenses/by-nc/4.0/) which permits any noncommercial use, distribution, and reproduction in any medium, provided the original author(s) and the source are cited. 
diabetes, ${ }^{12}$ preterm delivery, ${ }^{13}$ placental abnormalities, ${ }^{13}$ and first trimester bleeding. ${ }^{11,12,14}$ Oocyte donation is often associated with advanced maternal age, which is itself a known risk factor of adverse obstetric and perinatal outcomes. However, also in women of younger age, increased pregnancy complications such as hypertension have been reported in pregnancies using donor eggs. ${ }^{15}$

In Sweden, assisted reproductive treatments using donor eggs became approved in 2003. These treatments are exclusively provided by university hospitals that cover large healthcare regions, and the treatment costs are financed by the tax-funded healthcare system available to the whole population. Treatments with donor eggs require thorough physical and psychosocial screening of the egg recipient candidates and the treatments are restricted to women who are healthy at the time of attempting pregnancy. In Sweden, donor egg treatments are practiced under a strict policy of single embryo transfer to reduce identified potential pregnancy risks of multiple births. ${ }^{16,17}$

At present, there is a lack of reports on pregnancy outcomes in the specific group of women who have been previously treated for cancer and who become pregnant using donor eggs. Hence, the aim of our study was to assess the rates of obstetric and perinatal complications and identify particular risks of egg donor pregnancies in women previously treated for cancer, by comparing their outcomes to those of women similarly treated using donor eggs, but without cancer history.

\section{Materials and Methods}

We performed a prospective cohort study using the clinical registry of the Reproductive Medicine Clinic of Karolinska University Hospital since the egg donor program was initiated in 2003. All cases of iatrogenic infertility due to antineoplastic treatment, regardless of the type and stage of cancer at the moment of diagnosis and the interval between the cancer diagnosis and the donor egg treatment, were included. The women with a history of cancer (exposed group) underwent treatments using donor eggs to achieve pregnancy between 2003 and 2015 ( $n$ women $=31, n$ pregnancies $=25)$, and they were compared to women without cancer history, who underwent similar treatments during the same time period $(n$ women $=212, n$ pregnancies $=244)$. Demographic data, clinical data regarding assisted reproductive treatments, and details of cancer treatment were collected from the medical records. The cancer treatment data included whether or not RT was performed in the exposed group.

\section{Obstetric and perinatal outcome measures}

Obstetric outcomes were identified and extracted from the clinical database system through their corresponding ICD-10 (tenth revision of International Statistical Classification of Diseases). Diagnoses of interest included in the primary analysis were as follows: preeclampsia, eclampsia, HELLP syndrome, pregnancy-induced hypertension $(\mathrm{PIH})$, placental abruption, preterm premature rupture of membranes (PPROM), postpartum hemorrhage of $>1000 \mathrm{~mL}$ (PPH), placenta previa, Gestational Diabetes Mellitus (GDM), small for gestational age (SGA), and preterm birth (birth before a gestational age of 37 complete weeks) further subdivided into extreme $(<28$ weeks), very ( $28-<32$ weeks), and moderate (32-<37 weeks). Data on mode of delivery (Cesarean or vaginal), APGAR less than 7 at any point during the first 10 minutes after birth, and
$\mathrm{pH}<7$ at umbilical arterial blood were retrieved from the standardized maternal healthcare and delivery protocols provided by The Swedish National Board of Health and Welfare and used in the clinical registry at Nordic hospitals (Obstetrix $\left.{ }^{\circledR}\right)$. SGA was defined as a birth weight $<-2$ SD of the mean weight compared to the expected value for the gestational length according to the Swedish fetal growth standard. ${ }^{18}$

\section{Reproductive outcomes in women previously treated with RT}

Differences in reproductive outcomes using donor eggs in female cancer survivors with history of RT versus those without RT were studied in a subanalysis. Only the cases of RT with known impact on reproductive organs and ovarian function (such as total body irradiation [TBI] and abdominal or pelvic RT) were considered. ${ }^{19}$ Reproductive outcome measures included the thickness of endometrium (measured by ultrasonography on the day of embryo transfer [ET]), pregnancy rate (defined as positive $\mathrm{U}-\mathrm{hCG}$ per treatment), delivery rate (defined as delivery after gestational age of 22 weeks and 6 days), mean gestational age at birth, and weight at delivery.

\section{Statistical analysis}

Data were analyzed using logistic regression to estimate odds ratios (OR) and 95\% confidence intervals (CI). Women without history of cancer were used as the reference group in the regression models. Confounders considered for inclusion in the multiple logistic regression model were maternal age at $\mathrm{ET}$, as well as maternal body mass index $\left(\mathrm{BMI}, \mathrm{kg} / \mathrm{m}^{2}\right)$ at first antenatal visit (primary analysis of the whole cohort). There were very few smokers in either group; therefore smoking was not included as a confounder. Only observations with complete information on the included variables were included in the regression models, that is, complete case analysis. To account for the independent data structure (a woman contributed with more than one observation if she had more than one child), models were further adjusted for intrasibling correlation using a robust estimator of the standard error. ${ }^{20}$

SPSS (IBM Corp. Released 2014. IBM SPSS Statistics for Windows, Version 23.0; IBM Corp., Armonk, NY) and STATA (StataCorp. 2013. Stata Statistical Software: Release 13; StataCorp LP., College Station, TX) were used for the statistical analyses.

\section{Results}

During the study period, 31 women with a previous history of cancer (exposed group) were identified in the cohort. The women underwent 102 egg donor treatment cycles (52 with fresh embryos and 50 with cryopreserved embryos). The data on both successful ( $n$ women $=20, n$ pregnancies $=25$, all singleton) and unsuccessful pregnancy attempts were collected from the medical records.

The unexposed group included women who became pregnant though similar treatments using donor eggs at the same center, but did not have previous history of cancer ( $n$ women $=212, n$ pregnancies $=244$ ). Only the data on successful egg donor cycles that resulted in pregnancy and birth were included in the analysis.

Demographic data and clinical characteristics of the study cohort are presented in Table 1. There was no statistically 
Table 1. Clinical Characteristics of Women Who Achieved Pregnancy by Using Donor Eggs

\begin{tabular}{|c|c|c|c|c|c|c|}
\hline \multirow[b]{3}{*}{ Characteristic } & \multirow{3}{*}{$\begin{array}{l}\text { Unexposed } \\
\text { to cancer } \\
(244 \text { births })\end{array}$} & \multirow{3}{*}{$\begin{array}{l}\text { Exposed } \\
\text { to cancer } \\
(25 \text { births })\end{array}$} & \multirow[b]{3}{*}{$\mathrm{p}$-value } & \multicolumn{3}{|c|}{ Exposed to cancer stratified by radiotherapy ${ }^{\mathrm{a}}$ Yes/No } \\
\hline & & & & \multicolumn{3}{|c|}{$\begin{array}{l}\text { Only previous abdominal, pelvic, } \\
\text { or Total Body Irradiation were considered }\end{array}$} \\
\hline & & & & $R T$ (9 births) & No RT (16 births) & $\mathrm{p}$-value \\
\hline $\begin{array}{l}\text { Age at pregnancy } \\
\text { achieved by donor } \\
\text { egg treatment }(y)\end{array}$ & $35.1(24-42)$ & $33.7(24-42)$ & 0.09 & $31.1(24-42)$ & $35.2(31-40)$ & 0.019 \\
\hline $\begin{array}{l}\text { BMI } \\
\quad \text { Missing }\end{array}$ & $\begin{array}{c}23.9(16.0-38.9) \\
3\end{array}$ & $\begin{array}{c}24.3(19.7-35.2) \\
2\end{array}$ & 0.6 & $\begin{array}{c}23.9(19.7-30.1) \\
2\end{array}$ & $\begin{array}{c}24.5(19.8-35.2) \\
0\end{array}$ & 0.73 \\
\hline $\begin{array}{l}\text { Previous children } \\
\text { Yes } \\
\text { No } \\
\text { Missing }\end{array}$ & $\begin{array}{c}47(19.3 \%) \\
197(80.7 \%) \\
0\end{array}$ & $\begin{array}{c}6(27.3 \%) \\
16(72.7 \%) \\
3\end{array}$ & 0.37 & $\begin{array}{c}1(14.3 \%) \\
6(85.7 \%) \\
2\end{array}$ & $\begin{array}{c}5(33.3 \%) \\
10(66.7 \%) \\
1\end{array}$ & 0.35 \\
\hline $\begin{array}{l}\text { Smoking } \\
\text { Yes } \\
\text { No } \\
\text { Missing }\end{array}$ & $\begin{aligned} & 7(2.9 \%) \\
& 237(97.1 \%) \\
& 0\end{aligned}$ & $\begin{array}{c}1(5.3 \%) \\
18(94.7 \%) \\
6\end{array}$ & 0.56 & $\begin{array}{c}1(25 \%) \\
3(75 \%) \\
5\end{array}$ & $\begin{array}{c}0 \\
15(100 \%) \\
1\end{array}$ & 0.21 \\
\hline $\begin{array}{l}\text { Received ET/FET } \\
\text { ET } \\
\text { FET }\end{array}$ & $\begin{array}{l}141(57.8 \%) \\
103(42.2 \%)\end{array}$ & $\begin{array}{l}12(48 \%) \\
13(52 \%)\end{array}$ & 0.4 & $\begin{array}{l}4(44.4 \%) \\
5(55.6 \%)\end{array}$ & $\begin{array}{l}8(50 \%) \\
8(50 \%)\end{array}$ & 1.0 \\
\hline
\end{tabular}

The exposed cohort of cancer survivors ${ }^{\mathrm{b}}$ (Exposed group) was compared to women without cancer history, who underwent similar treatments (Unexposed group). Data on previous treatment with abdominal/pelvic radiotherapy or total body irradiation in the exposed group are also presented.

Data are mean (range) or percentages.

${ }^{a}$ Radiotherapy defined as radiotherapy of abdomen/pelvis or total body irradiation.

${ }^{\mathrm{b}}$ Irrespective of timing of cancer diagnosis in relation to birth.

$\mathrm{RT}$, radiotherapy; BMI, body mass index; ET, embryo transfer; FET, frozen embryo transfer.

significant difference in age, BMI, parity, smoking habits, or proportion of fresh and frozen embryo transfers (FET) between the groups. Among the women with previous history of cancer, the mean age was lower in the group who received RT (31.1 years) compared to the group who did not (35.2 years).

Table 2 reports obstetric and perinatal outcomes for the exposed and the unexposed groups. Women with a history of cancer who achieved pregnancy using donor eggs had higher risks for several complications compared to women without previous cancer history.

In the exposed group, 26\% (6 of 23) of pregnancies were complicated with preeclampsia, compared to $13 \%$ (32 of 243) of pregnancies in the unexposed group. The relative difference in odds was statistically significant after adjustment for women's age at first antenatal visit and BMI (aOR: $2.79,95 \%$ CI: 1.07-7.34).

The incidence of preterm birth (PTB) ( $<37$ weeks of gestation) was significantly higher in women previously treated for cancer. The mean gestational week at delivery was 36.9 in the exposed group and 39.3 in the control group. Stratifying for extreme $(<28$ weeks), very ( $<32$ weeks), and moderate ( $<37$ weeks) prematurity, we found that the risk for very preterm birth was several fold increased in the exposed group (aOR: 17.4, 95\% CI: 3.99-75.79).

The incidence of PPROM was also higher among cancer survivors in the unadjusted analysis, but when adjusted for BMI and age, this difference was not longer statistically significant. In the exposed group, of nine women with PTB, four had delivered prematurely due to PPROM and two due to PE. There were no cases of iatrogenic preterm birth without clear pathology or indication in this cohort.

The percentage of Cesareans (CS) was high in both the groups, $48 \%$ (12 of 25) in the exposed group and 43\% (106 of
244) in the unexposed group, compared to a general CS rate of $17 \%$ in Sweden. ${ }^{21}$

Gestational diabetes was infrequent in the cohort, with only two cases of GDM identified in the unexposed group (2/ $244=0.08 \%$ ) and no cases of GDM in the exposed group. The general prevalence of hypertensive disorders of pregnancy was $19 \%$ (46 of 243 ) versus $26 \%$ (6 of 23), respectively.

The rate of postpartum hemorrhage, $\mathrm{PPH}$ defined as bleeding over $1000 \mathrm{~mL}$, was $32 \%$ ( 7 of 22) in the exposed group and $27 \%$ (65 of 243) in the unexposed group. No cases of placental abruption or placenta previa were registered in the exposed group, while there were two cases of placenta previa and five cases of placental abruption in the unexposed group.

Apgar score below seven during the first 10 minutes after birth was rare among newborns in both exposure groups and no statistically significant difference was observed. Care at the Neonatal Intensive Care Unit was required for 24\% (5 of 21) of babies born to women with the history of cancer compared to $18.5 \%$ (45 of 243) of babies born to women without previous cancer history. The mean birth weight was significantly lower in the exposed group than in the unexposed group ( $2914 \mathrm{~g}$ vs. $3386 \mathrm{~g}$, respectively). The mean gestational week at birth was 36.9 versus 39.3 , respectively.

There was 1 case of intrauterine fetal death in the unexposed group. No maternal deaths have occurred.

\section{Analysis of patients with a history of RT in the cohort}

To test for the possible influence of RT on reproductive outcomes of egg donation, we have stratified the women with cancer history into two groups: one including 15 women who 
Table 2. Obstetric and Perinatal Outcomes of Cancer Survivors Who Achieved Pregnancy Using Donor Eggs (Exposed Group) Compared to Women Without Cancer History Who Achieved Pregnancy by Similar Treatments (UneXPosed Group)

\begin{tabular}{lcccc}
\hline Outcome & $\begin{array}{c}\text { Unexposed } \\
\text { group } n / N\end{array}$ & $\begin{array}{c}\text { Exposed } \\
\text { group } n / N\end{array}$ & OR $^{\mathrm{a}}(95 \%$ CI $)$ & OR $^{\mathrm{b}}(95 \%$ CI $)$ \\
\hline Preeclampsia & $32 / 243$ & $6 / 23$ & $2.33(0.89-6.10)$ & $2.79(1.07-7.34)$ \\
Pregnancy-induced hypertension & $14 / 243$ & 0 & & \\
Hypertensive disorders of pregnancy & $46 / 243$ & $6 / 243$ & $1.51(0.59-3.89)$ & $1.80(0.69-4.69)$ \\
Placental abruption & $5 / 243$ & 0 & & \\
PPROM & $11 / 243$ & $4 / 23$ & $4.44(1.30-15.17)$ & $3.85(0.96-15.42)$ \\
Hemorrhage (>1000 mL) & $65 / 243$ & $7 / 22$ & $1.28(0.40-4.06)$ & $1.22(0.34-4.38)$ \\
Caesarean & $106 / 244$ & $12 / 25$ & $1.20(0.46-3.12)$ & $0.99(0.36-2.76)$ \\
Previa & $2 / 243$ & 0 & & \\
GDM & $2 / 244$ & 0 & & \\
SGA & $6 / 244$ & $1 / 25$ & $1.65(0.19-14.59)$ & $2.12(0.24-18.68)$ \\
NICU & $45 / 243$ & $5 / 21$ & $1.38(0.48-3.98)$ & $1.14(0.36-3.61)$ \\
All preterm births (<37 weeks) & $23 / 244$ & $9 / 25$ & $5.41(2.08-14.02)$ & $5.54(2.01-15.31)$ \\
Extreme preterm birth & $3 / 244$ & $1 / 25$ & $3.35(0.33-33.93)$ & \\
Very preterm birth & $3 / 244$ & $4 / 25$ & $15.3(3.24-72.37)$ & $17.39(3.99-75.79)$ \\
Moderate preterm birth & $17 / 244$ & $4 / 25$ & $2.54(0.76-8.57)$ & $2.92(0.88-9.66)$ \\
Mean (range) gestational week at birth & $39.3(23.9-42.1)$ & $36.9(27.1-41.4)$ & & \\
Mean (range) birth weight (g) & $3386(440-5175)$ & $2914(1000-4500)$ & & \\
APGAR <7 & $5 / 243$ & $1 / 21$ & $2.38(0.26-21.90)$ & $2.40(0.24-24.46)$ \\
pH <7 & $1 / 244$ & $0 / 22$ & & \\
\hline
\end{tabular}

$\mathrm{OR}^{\mathrm{a}}=$ Unadjusted odds ratios with $95 \%$ confidence intervals (CI) estimated from logistic regression. The model is adjusted for intrasibling correlation using a robust estimator of the standard error.

$\mathrm{OR}^{\mathrm{b}}=$ Odds ratios with $95 \%$ confidence intervals estimated from logistic regression, adjusted for BMI (linear effect) and maternal age at first antenatal visit (linear effect). The model is adjusted for intrasibling correlation using a robust estimator of the standard error.

Only observations with complete information on the included variables were included, that is, complete case analysis.

PPROM, preterm premature rupture of membranes; GDM, Gestational Diabetes Mellitus; SGA, small for gestational age; NICU, neonatal intensive care unit.

received RT (abdomen/pelvis/TBI) and the second group including 16 women who received chemotherapy, surgery, or the combination of both (altogether 31 women with $102 \mathrm{egg}$ donor treatment cycles, including both successful and unsuccessful pregnancy attempts). Two women who had received RT of the thorax were not included in the RT group, as they did not receive pelvic or abdominal RT.

Demographic data and clinical characteristics of female cancer survivors with and without history of RT are presented in Table 3. Women in the RT group were younger $(p<0.001)$, had a lower BMI $(p=0.005)$, and presented with significantly thinner endometrium thickness estimated during their treatment cycle $(p<0.001)$ than the women in the group without history of RT to pelvis/abdomen or TBI.

Preterm births were more common in the RT group, resulting in the mean delivery week 34.9 and mean birth weight $2580 \mathrm{~g}$ compared to 38 weeks and $3101 \mathrm{~g}$ in the no-RT group. A high rate of Cesarean deliveries was noted in the both groups, 55\% in the RT (5 of 9) group and 44\% (7 of 16) in the no-RT group. There was no statistically significant difference regarding pregnancy rate $(23 \%$ vs. $36 \%, p=0.2)$, live birth rate $(19 \%$ vs. $29 \%, p=0.3)$ or delivery per pregnancy rate $(82 \%$ vs. $80 \%$, $p=0.9$ ) in women treated with RT versus those who did not.

\section{Discussion}

To our knowledge, this is the first study that investigates the specific maternal and perinatal risks in pregnancies achieved using donor eggs among women with a previous history of cancer. Our results suggest that in these pregnan- cies, women previously treated for cancer have an increased risk of PTB and preeclampsia compared to women without cancer history. In an analysis limited to women with a history of cancer, women who received pelvic or abdominal RT presented with significantly thinner endometrium than women who were treated with other modalities.

Increased risk of PTB is well documented among egg donor pregnancies. ${ }^{22-24}$ However, in our patient material of women who had undergone careful screening and were judged healthy enough for egg donation treatment, this risk was further increased (greater than fivefold) if they had a previous history of cancer. Differences in the incidence of very preterm birth (between 28 and 32 gestational weeks) were the most prominent ones.

An increased level of anxiety due to previous history of cancer and egg donation achieved pregnancy could be possibly expected among both the women and their obstetricians, making them more prone to choose a planned preterm delivery to avoid further potential risks. Still, no cases of iatrogenic PTB without a clear indication or pathology were noted in this cohort. Most of the cases of PTB were due to PPROM or PE. Both PE and PPROM can therefore be considered to be mediators. In general, these cases were few to allow some definite conclusions about the causal association between PTB and the previous history of cancer.

Hypertensive disorders of pregnancy include four categories: chronic hypertension, preeclampsia-eclampsia, preeclampsia superimposed on chronic hypertension, and gestational hypertension. ${ }^{25}$ Risk of developing hypertensive disorders of pregnancy was high in both groups in our cohort, 
Table 3. Main Characteristics of Cancer Survivors According to Treatment with Abdominal/Pelvic Radiotherapy or Total Body IrRadiation Received (RT Yes), or No Radiotherapy Received (RT No)

\begin{tabular}{|c|c|c|c|c|}
\hline Characteristic & $\begin{array}{l}\text { Total } \\
31 \text { women, } \\
102 \text { cycles }\end{array}$ & $\begin{array}{c}R T \text { Yes } \\
N(\%) 15 \text { women } \\
47 \text { cycles } \\
(21 \text { FET }+26 \text { ET })\end{array}$ & $\begin{array}{c}R T \text { No } \\
N(\%) 16 \text { women, } \\
55 \text { cycles } \\
(29 \text { FET }+26 E T)\end{array}$ & $\mathrm{p}$-value ${ }^{a}$ \\
\hline Age at cancer diagnosis (y) & $20.2(3-38)$ & $17.1(3-27)$ & $22.9(7-38)$ & 0.001 \\
\hline $\begin{array}{l}\text { Average interval (years) between } \\
\text { cancer diagnosis and egg } \\
\text { donor treatment }\end{array}$ & $14.9(2-34)$ & $16.2(5-34)$ & $13.75(2-31)$ & 0.171 \\
\hline Age at egg donor treatment (y) & $35.1(24-45)$ & $33.3(24-42)$ & $36.6(31-45)$ & $<0.001$ \\
\hline BMI $\left(\mathrm{kg} / \mathrm{m}^{2}\right)$ & $24.9(20-28)$ & $23.8(20-27)$ & $26.25(23-28)$ & 0.005 \\
\hline Smokers & $5 / 67(7.5 \%)$ & $3 / 25(12 \%)$ & $2 / 42(4.8 \%)$ & 0.354 \\
\hline $\begin{array}{l}\text { Endometrium thickness } \\
\text { by ultrasonography (mm) }\end{array}$ & $8.2(4-14.2)$ & $7.4(4-12)$ & $9(5-14.2)$ & $<0.001$ \\
\hline \multicolumn{5}{|l|}{ Type of cancer $(\mathrm{N}$ of women $=31)$} \\
\hline Leukemia & 13 & 11 (TBI) & 2 & \\
\hline Hodgkin/non-Hodgkin lymphomas & 5 & 1 (TBI) & 4 & \\
\hline Ovarian & 6 & 0 & 6 & \\
\hline Wilms & 3 & 2 (abdominal) & 1 & \\
\hline Other & 4 & 1 (pelvic) & 3 & \\
\hline \multicolumn{5}{|l|}{ Reproductive outcome } \\
\hline Pregnancy & $31(30.4 \%)$ & $11(23.4 \%)$ & $20(36.4 \%)$ & 0.197 \\
\hline Live birth ${ }^{b}$ & $25(24.5 \%)$ & $9(19.1 \%)$ & $16(29.1 \%)$ & 0.260 \\
\hline Miscarriage $^{c}$ & $5 / 31(19.4 \%)$ & $1 / 11(18.2 \%)$ & $4 / 20(20 \%)$ & 0.902 \\
\hline Ectopic $^{\mathrm{c}}$ & $1 / 31$ & $1 / 11$ & $0 / 20$ & 0.171 \\
\hline Pregnancy weeks at delivery (mean) & $36.9(27.1-41.4)$ & $34.9(27.1-39.9)$ & $38.0(30.6-41.4)$ & 0.079 \\
\hline Mean birth weight $(\mathrm{g})$ & $2914(1000-4500)$ & $2580(1000-3985)$ & $3101(1975-4500)$ & 0.19 \\
\hline \multicolumn{5}{|l|}{ Mode of delivery } \\
\hline Vaginal & 11 & 3 & 8 & \\
\hline Cesarean section & 12 & 5 & 7 & \\
\hline Instrumental & 2 & 1 & 1 & \\
\hline
\end{tabular}

Reproductive outcomes after egg donor treatments by RT groups (Yes vs. No) are also presented.

Data are mean (range) or $\mathrm{n} / \mathrm{N}$ with percentages.

Among the 31 women, 13 were survivors of cancer in childhood (younger than 18 years at the time of cancer treatment).

${ }^{a} \chi^{2}$-test for factor variables and $t$-test (assuming independent observations and equal variances) for the continuous variables.

${ }^{\mathrm{b}}$ Percentage per cycle.

${ }^{c}$ Percentage per pregnancy.

TBI, total body irradiation.

but the risk of a more severe variant (preeclampsia) was 2.7fold higher in the group exposed to prior cancer therapy. Multiple previous studies have reported increased frequency of pregnancy-induced hypertensive complications in egg donor pregnancies compared to both IVF/ICSI and spontaneously conceived pregnancies. ${ }^{9,11,22,23,26,27}$ This risk does not appear to be correlated with the technique of fertilization or maternal age. ${ }^{27}$ Moreover, in the study of Keegan et al., young women treated with egg donation presented with the highest rate of PIH. ${ }^{15}$ The complex immunological interaction that exists in the fetal-placental unit is often discussed as a possible origin of the increased risk for pregnancy hypertensive disorders in oocyte recipients. ${ }^{27-29}$ If the effect of this immunologic interaction could be further amplified by the history of cancer itself or by some specific sequelae of antineoplastic treatments in the vasculature with compromised placental blood flow, should be investigated in future studies of a larger scale.

The rates of Cesareans were high in both groups, consistent with the results of previous studies claiming association of egg donation with high Cesarean rates. ${ }^{26,30}$ In our material, the information about Cesareans' indications was not complete, and therefore a detailed analysis was not possible. The high risk of postpartum hemorrhage observed in both groups could probably reflect the high Cesarean rates that were found.

The mean birth weight was lower in the exposed group, reasonably due to the higher rate of PTB, as we could not find any significant difference in the rates of SGA between the groups. No statistically increased risk for adverse neonatal outcomes estimated as a low Apgar score, umbilical cord $\mathrm{pH}$ $<7$, or the need of ward at the Neonatal Intensive Care Unit was identified in the exposed group, despite a significantly higher rate of PTB. However, these results should be interpreted with caution due to the limited size of the study groups, and particularly a small exposed group.

The results of our subanalysis demonstrated that women with a history of RT, either abdominal/pelvic or TBI, had a significantly thinner endometrium estimated by ultrasonography compared with women who had not received RT. Also, a nonsignificant trend toward lower pregnancy rates and live birth rates per ET, and a higher risk of preterm delivery were found in women with previous RT. These findings are consistent with the previous reports, indicating that reproductive outcomes after RT seem to be worse than outcomes after chemotherapy or surgery. ${ }^{5,6,31}$ 
Strengths of our study include its prospective design and adjustment of results for the potential confounders. Both the exposed and unexposed groups had their treatments at one center and were comparable as regard to age, BMI, and smoking habits. Moreover, all candidates for egg donor treatments in Sweden undergo a strict physical and psychosocial screening, regardless of the reason for donor egg requirement, and the women have to be healthy, with no obvious contraindication to pregnancy, and younger than 40 years of age at time of starting the treatment. Therefore, the women in the exposed group of our study represent a homogeneous group of the most healthy female cancer survivors, who developed ovarian failure due to their treatment, even though cancer is a heterogeneous disease and the antineoplastic treatments received could be different among them.

The major limitation of our study was a small sample size and few events. Despite the aim to control for main confounders, some of the variables with potential impact on the results were not possible to address. For example, the indication for oocyte donor treatment in the unexposed group, the age of the oocyte donors, or the egg quality could also have potential effects on perinatal outcomes and would be interesting to consider in future studies. Also, this single-center study was not able to identify specific explanation to the association between previous history of cancer and increased risk of PTB and preeclampsia in the recipients of donor eggs. However, to our knowledge, this is the first and largest cohort to date that provides detailed data on obstetric and perinatal outcomes of pregnancies using donor eggs in female cancer survivors who become infertile as a sequela of their cancer treatment. A "healthy mother effect" (i.e., women who are healthy give birth and those who are affected by the disease do not) is often discussed as at least a partial explanation of the fact that women who get pregnant after oncological treatments seem to survive similar or even longer compared to nonpregnant controls with a history of cancer. ${ }^{32-36}$ Perhaps the same effect may influence maternal and perinatal outcomes of donor egg pregnancies in cancer survivors, as the women who may attempt those treatments have to become healthy enough to be able to qualify for such treatment. It would be interesting to address this question in the design of future studies.

\section{Conclusion}

The egg donor pregnancies in women previously treated for cancer were in our study, associated with higher risk for PTB and preeclampsia, in addition to other known risks associated with egg donor treatments. Further studies to confirm this are needed. Careful evaluation and counseling before conception, as well as close monitoring of pregnancy (blood pressure controls, awareness of symptoms of preeclampsia, and threatening PTB), should be recommended. Overall, maternal and perinatal outcomes in the studied group appear to be reassuring and the use of donor eggs to achieve pregnancy in women with iatrogenic ovarian failure after cancer treatments should be encouraged.

\section{Authors' Contributions}

Conception and design: Anna Marklund and Kenny Rodriguez-Wallberg.
Financial and administrative support: Kenny RodriguezWallberg.

Provision of study material or patients: Kenny Rodriguez-

Wallberg.

Collection and assembly of data: All authors.

Data analysis and interpretation: All authors.

Article writing: All authors.

Final approval of article: All authors.

Accountable for all aspects of the work: All authors.

\section{Acknowledgments}

The authors thank Sandra Eloranta at Scandinavian Development Services for expert statistical advice and Christina Scherman-Pukk and Lena Hyberg at the clinic of Reproductive Medicine of Karolinska University Hospital for their assistance in data collection. This study was funded by grants from the Swedish Cancer Childhood Foundation, Radiumhemmets Research Grants, The Swedish Breast Cancer Association, Stockholm County Council, and Karolinska Institutet to KARW.

\section{Ethics Approval}

The study was approved by the Regional Ethical Review board in Stockholm, Sweden (Dnr 2011/1758-31/2 and Amendment 2014/470-32).

\section{Author Disclosure Statement}

No competing financial interests exist.

\section{References}

1. Armuand GM, Wettergren L, Rodriguez-Wallberg KA, Lampic C. Desire for children, difficulties achieving a pregnancy, and infertility distress 3 to 7 years after cancer diagnosis. Support Care Cancer 2014;22:2805-2812.

2. Geue K, Richter D, Schmidt R, et al. The desire for children and fertility issues among young German cancer survivors. J Adolesc Health 2014;54:527-535.

3. Rodriguez-Wallberg KA, Oktay K. Fertility preservation during cancer treatment: Clinical guidelines. Cancer Manag Res 2014;6:105-117.

4. Chow EJ, Stratton KL, Leisenring WM, et al. Pregnancy after chemotherapy in male and female survivors of childhood cancer treated between 1970 and 1999: A report from the Childhood Cancer Survivor Study cohort. Lancet Oncol 2016;17:567-576.

5. Urbano MT, Tait DM. Can the irradiated uterus sustain a pregnancy? A literature review. Clin Oncol (R Coll Radiol) 2004;16:24-28.

6. Critchley HO, Bath LE, Wallace WH. Radiation damage to the uterus-review of the effects of treatment of childhood cancer. Hum Fertil (Camb) 2002;5:61-66.

7. Green DM, Lange JM, Peabody EM, et al. Pregnancy outcome after treatment for Wilms tumor: A report from the national Wilms tumor long-term follow-up study. J Clin Oncol 2010;28:2824-2830.

8. Younis JS, Laufer N. Oocyte donation is an independent risk factor for pregnancy complications: The implications for women of advanced age. J Womens Health (Larchmt) 2015;24:127-130. 
9. Savasi VM, Mandia L, Laoreti A, Cetin I. Maternal and fetal outcomes in oocyte donation pregnancies. Hum Reprod Update 2016;22:620-633.

10. Pecks U, Maass N, Neulen J. Oocyte donation: A risk factor for pregnancy-induced hypertension: A meta-analysis and case series. Dtsch Arzteblatt Int 2011;108:23-31.

11. Stoop D, Baumgarten M, Haentjens P, et al. Obstetric outcome in donor oocyte pregnancies: A matched-pair analysis. Reprod Biol Endocrinol 2012;10:42.

12. Sheffer-Mimouni G, Mashiach S, Dor J, Levran D, Seidman DS. Factors influencing the obstetric and perinatal outcome after oocyte donation. Hum Reprod 2002;17:2636-2640.

13. Wolff KM, McMahon MJ, Kuller JA, Walmer DK, Meyer WR. Advanced maternal age and perinatal outcome: Oocyte recipiency versus natural conception. Obstet Gynecol 1997;89:519-523.

14. Klatsky PC, Delaney SS, Caughey AB, Tran ND, Schattman GL, Rosenwaks Z. The role of embryonic origin in preeclampsia: A comparison of autologous in vitro fertilization and ovum donor pregnancies. Obstet Gynecol 2010; 116:1387-1392.

15. Keegan DA, Krey LC, Chang HC, Noyes N. Increased risk of pregnancy-induced hypertension in young recipients of donated oocytes. Fertil Steril 2007;87:776-781.

16. Sveriges Kommuner och Landsting. Rekommendation om enhetlighet $\mathrm{i}$ landstingens och regionernas erbjudande av offentligt finansierad assisterad befruktning. Available at: https:// skl.se/download/18.3f360f81154baabbb531975d/146400570 1156/SKL-Rekommendation-assisterad-befruktning-forslag20160419.pdf Accessed April 9, 2018.

17. Lag (2006:351) om genetisk integritet m.m. Svenska författningssamling 2006:351. Available at: www.riksdagen.se/ sv/dokument-lagar/dokument/svensk-forfattningssamling/ lag-2006351-om-genetisk-integritet-mm_sfs-2006-351. Accessed April 9, 2018.

18. Marsal K, Persson PH, Larsen T, Lilja H, Selbing A, Sultan B. Intrauterine growth curves based on ultrasonically estimated foetal weights. Acta Paediatr 1996;85:843-848.

19. Rodriguez-Wallberg KA, Oktay K. Fertility preservation medicine: Options for young adults and children with cancer. J Pediatr Hematol Oncol 2010;32:390-396.

20. Rogers WH. Regression standard errors in clustered samples. Stata Tech Bull Reprints 1993;13:19-23.

21. Graviditetsregistret. Arsrapport 2014. Accessed September 9, 2016.

22. Nejdet S, Bergh C, Kallen K, Wennerholm UB, ThurinKjellberg A. High risks of maternal and perinatal complications in singletons born after oocyte donation. Acta Obstet Gynecol Scand 2016;95:879-886.

23. Malchau SS, Loft A, Larsen EC, et al. Perinatal outcomes in 375 children born after oocyte donation: A Danish national cohort study. Fertil Steril 2013;99:1637-1643.
24. Dude AM, Yeh JS, Muasher SJ:.Donor oocytes are associated with preterm birth when compared to fresh autologous in vitro fertilization cycles in singleton pregnancies. Fertil Steril 2016;106:660-665.

25. Report of the National High Blood Pressure Education Program Working Group on High Blood Pressure in Pregnancy. Am J Obstet Gynecol 2000;183:S1-S22.

26. Elenis E, Svanberg AS, Lampic C, Skalkidou A, Akerud $\mathrm{H}$, Sydsjo G. Adverse obstetric outcomes in pregnancies resulting from oocyte donation: A retrospective cohort case study in Sweden. BMC Pregnancy Childbirth 2015; $15: 247$.

27. Tranquilli AL, Biondini V, Talebi Chahvar S, Corradetti A, Tranquilli D, Giannubilo S. Perinatal outcomes in oocyte donor pregnancies. J Matern Fetal Neonatal Med 2013;26: 1263-1267.

28. Serhal PF, Craft I. Immune basis for pre-eclampsia evidence from oocyte recipients. Lancet 1987;2:744.

29. Letur H, Peigne M, Ohl J, et al. Hypertensive pathologies and egg donation pregnancies: Results of a large comparative cohort study. Fertil Steril 2016;106:284-290.

30. Soderstrom-Anttila V. Pregnancy and child outcome after oocyte donation. Hum Reprod Update 2001;7:28-32.

31. Munoz E, Fernandez I, Martinez M, et al. Oocyte donation outcome after oncological treatment in cancer survivors. Fertil Steril 2015;103:205-213.

32. Azim HA, Jr., Kroman N, Paesmans M, et al. Prognostic impact of pregnancy after breast cancer according to estrogen receptor status: A multicenter retrospective study. J Clin Oncol 2013;31:73-79.

33. Peccatori FA, Azim HA, Jr. Safety of pregnancy following breast cancer diagnosis. Acta Oncol 2009;48:470-471; author reply 471.

34. Sankila R, Heinavaara S, Hakulinen T: Survival of breast cancer patients after subsequent term pregnancy: "healthy mother effect'. Am J Obstet Gynecol 1994;170:818-823.

35. Gelber S, Coates AS, Goldhirsch A, et al. Effect of pregnancy on overall survival after the diagnosis of early-stage breast cancer. J Clin Oncol 2001;19:1671-1675.

36. de Corbiere P, Ritzel K, Cazabat L, et al. Pregnancy in Women Previously Treated for an Adrenocortical Carcinoma. J Clin Endocrinol Metab 2015;100:4604-4611.

Address correspondence to: Kenny A. Rodriguez-Wallberg, MD, PhD Department of Oncology-Pathology Karolinska Institutet Stockholm 17177 Sweden

E-mail: kenny.rodriguez-wallberg@ki.se 